\title{
Scientific Discourse: Can Our First-Year Students Express Themselves in Science?
}

\section{Marnel Mouton ${ }^{1}$, Ilse Rootman-Le Grange ${ }^{2}$}

${ }^{1}$ Department of Botany and Zoology, Faculty of Science, Stellenbosch University, Matieland, South Africa, ${ }^{2}$ Faculty of Science, Stellenbosch University, Matieland, South Africa.

\begin{abstract}
Scientific discourse is a specialized, semantically dense language used to formulate clear, objective arguments around experimental results. However, science classrooms are practically void of scientific argumentation and this important skill is rarely modelled or developed in these spaces. Yet, students are expected to engage with complex disciplinary texts and then demonstrate their mastery of scientific subject matter using appropriate scientific discourse. Students find this extremely challenging and many are implicitly excluded from successful engagement with the subject.
\end{abstract}

The aim of our study was the assessment and development of first-year biology students' scientific discourse skills through collaborative pedagogy, to make aspects of biology discourse explicit to all students. We drew on Legitimation Code Theory's concept of semantic density, which considers complexity of meaning, to design a learning opportunity and then analyzed selections of students' summative assessments.

Results showed profound variation in the proficiency of the students' scientific vocabulary and language functions, and the discourse of the school and firstyear biology textbooks. We therefore argue for science pedagogy that would allow students time and opportunities to mindfully engage with complex disciplinary text and then demonstrate their mastery of their learning using appropriate scientific discourse.

Keywords: Science discourse; skills; Legitimation Code Theory; semantic density. 


\section{Introduction}

Scientific discourse is a semantically dense specialized language (Marshall \& Case 2010; Ambitious Science Teaching 2015) as it involves argumentation which proposes rational explanations of empirical data. Scientists use language in a very specific way to present their findings, construct their arguments and probable explanations, share ideas and draw conclusions (Krajcik \& Sutherland 2010).

Current science classrooms, however, do very little to model scientific practices or develop its specialized discourse. Most still follow a traditional lecturing format where instructors tend to do most of the communicating, not encouraging participation in scientific argumentation, sharing of ideas or understanding (Ambitious Science Teaching 2015; Archila et al. 2018). Students, however, need to become familiar with and skilled in using the specialized language and argumentation in science. Educational researchers therefore petition for the "rules of the game" to be made explicit to the students. This is why more opportunities are needed for students to engage with the language, practices, "values and ways of thinking" in science. If not, they will implicitly be excluded from successful engagement with the subject (Marshall \& Case 2010; Case et al. 2013). Science lecturers are after all the "insiders" of their discipline, and as such have a responsibility to allow their students, the "outsiders" entry into the disciplinary community and its practices, by teaching them "the rules of the game" (Marshall \& Case 2010). The code of conduct in science should thus be taught in science classrooms by modelling its "ways of reasoning", practices and the use of science discourse (Ambitious Science Teaching 2015).

McNeill et al. (2005) showed that scientific discourse is demanding for the majority of students, even for English-speaking students writing in their home language. It is therefore necessary to also consider the impact of students' general language proficiency on their ability to use scientific discourse. In many higher education environments (such as South Africa), a large proportion of the students do not speak English at home, although many are instructed in English (Jacobs 2007; Archila et al. 2018). According to Boughey (2002), problems surface when students struggle to "manipulate the forms of the additional language in a way that would allow them to receive and pass on the thoughts developed in the disciplines." Some authors consequently argue for a pedagogy that will recognize that students may not have the necessary language skills required to succeed in some disciplines such as the sciences (Hurst 2010; Kirby 2010). Moreover, Maton (2013) pointed out that there is often a disconnection between complex disciplinary reading which he termed "high stakes reading", and the production of appropriate discourse, also known as "high stakes writing". Thus, students need to attain a certain level of language proficiency for them to gain epistemological access in general (Valencia 2014). This challenge led many institutions of higher education to introduce academic literacy (AL) components to their undergraduate offerings, with free-standing modules being the most dominant format (Boughey 2002; 
Jacobs 2007). There are however a substantial number of papers that argue AL being most effective when part of a collaborative pedagogical approach, thus where AL practitioners and disciplinary specialists collaborate to develop language skills within the disciplines (Boughey 2002; Jacobs 2007; Case et al. 2013).

Science students need to be given opportunities to develop and practice their general language proficiency, but also fundamental skills in science, including argumentation, the use of evidence to support knowledge claims, constructing hypotheses about scientific phenomena and writing up experiments according to scientific procedures. Such pedagogy involves students in metacognitive activities where they have to consider how to communicate their scientific thinking, while also reflecting and clarifying their thoughts in the process (Institute for Inquiry 2015), thereby developing their discourse while improving their scientific reasoning (Dirrigl \& Noe 2018). The aim of this study was to gain insight into first-year students' use of scientific discourse and explore ways to develop this fundamental skill. Furthermore, we aimed to gain insight into how lecturers can support students' development of scientific discourse by assisting them in the transition towards higher levels of discipline complexity and content volume.

\section{Theoretical Framework: Legitimation Code Theory}

Legitimation Code Theory (LCT) is a social realist framework that considers knowledge practices. It is a multidimensional toolkit that offers different dimensions to analyze particular sets of organizing principles, also known as legitimation codes, which underlie these practices. LCT conceptualizes complexity of meaning as semantic density (Maton 2013, 2014a, 2014b).

Scientific discourse represents complex condensed meaning and therefore strong semantic density. Moreover, semantic density also conceptualizes complexity in terms of the condensation of meaning within a practice, and furthermore explores the relationality of meanings. Thus, scientific terms or concepts that have a number of relations to other meanings (also known as a 'constellations' of meanings), represent stronger semantic density. Studies showed that in knowledge practice such as pedagogy, recurring shifts between more complex and simpler meaning (stronger and weaker semantic density), also known as semantic waves, are essential to support cumulative knowledge building for all students (Maton 2013). Furthermore, the use of complex language in discourse is also associated with these semantic shifts (Martin 2013).

The rationale of this study was therefore to use the concept of semantic density to assess students' science discourse, but also to teach these newcomers the "rules of the game" within the discipline, and thereby develop their scientific discourse, prior to summative assessments when well-developed scientific language and writing is expected. 


\section{Methodology}

\subsection{Project-based, Collaborative Pedagogy as Learning Opportunity}

We identified a specific section of a first-year biology curriculum where students typically find it difficult to engage with their first-year textbook and then formulate their understanding using appropriate scientific discourse during summative assessments. We decided to follow a project-based learning approach (PBL; Lee et al. 2014) to allow students time and opportunity for engagement with this relatively new level of discourse before having to demonstrate their understanding and proficiency during a summative assessment. To further model the importance of language skills in scientific writing to these first-year students, the project was implemented as a collaboration between the biology lecturer and the academic literacies lecturers from the Language Center at Stellenbosch University (collaborative pedagogy; Jacobs 2007). Following this learning opportunity, six randomly selected students' test papers from a cohort-representative range of achievement levels were used to perform the semantic density analysis. This process involved assigning each word in the students' discourse to a category in the translation device with an assigned numerical value (Figure 1), to reveal the semantic profile of the discourse. The semantic profiles exposed the students' use of appropriate scientific discourse, varying between complex condensed meaning and simpler meaning of everyday discourse, thus semantic waves. Data from one of the analyzed concepts is presented in this paper: the description of the eukaryotic nucleus.

\subsection{Translation Device for the Analyses of Epistemic Semantic density}

Maton and Doran (2016) proposed an extensive translation device for discerning how epistemic-semantic density (ESD) realize in discourse (Figure 1). This translation device allows us to distinguish between higher-level scientific concepts that represent very complex meaning, and more mundane talk (simpler meaning) in discourse. Thus, it can be used to analyze the complexity of meaning expressed by the words in the discourse, and, how meaning may be added or increased through combining words with additional words. The translation device therefore provides an indication of the relative complexity of meaning or semantic density, at the level of words and wording. 

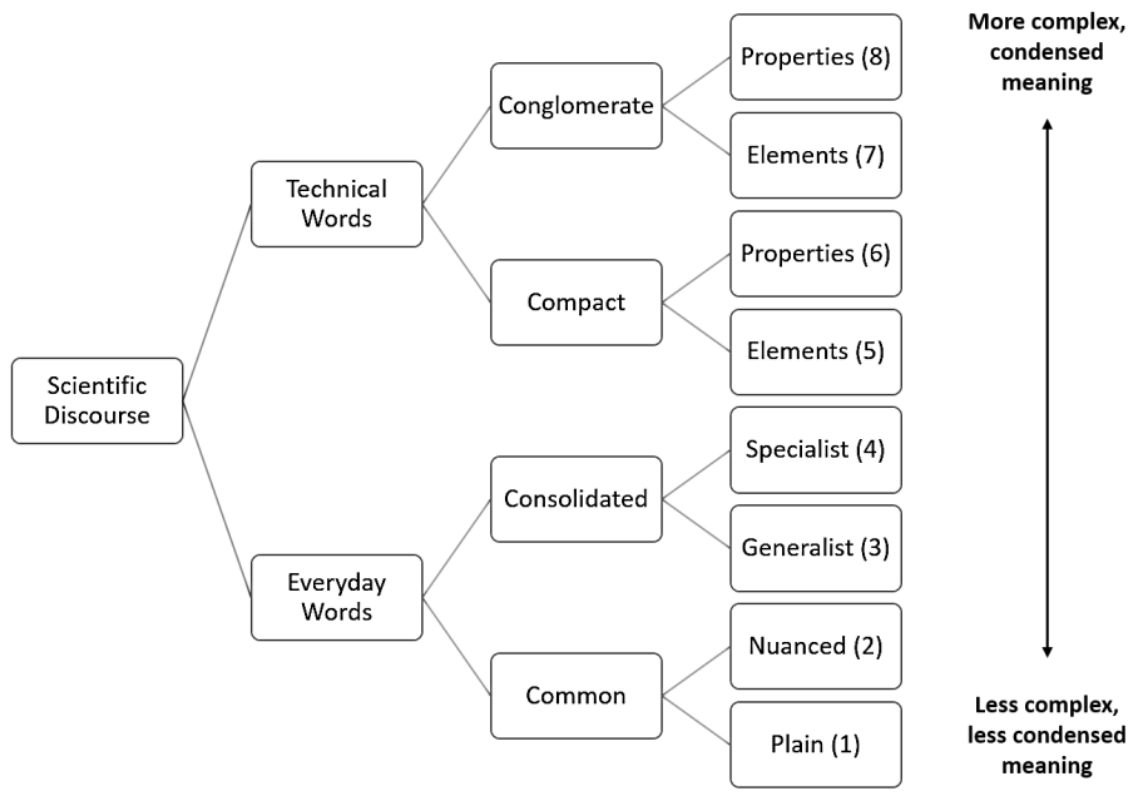

Figure 1. The wording tool (Maton and Doran 2016) for the analysis of complexity of meaning, also known as epistemic semantic density. The device shows the range of categories of words, varying from simpler meaning (bottom) towards complex condensed meaning (top).

\section{Results and Discussion}

Our analyses of the students' biology discourse showed that their proficiency varied substantially across the group as shown by the longer and shorter bars in Figure 2. Firstly, it became evident that the scientific vocabulary of the students varied substantially, with some students showing mastery of the content terminology (complex meaning), as well as the ability to demonstrate how these terms relate to one another within constellations of meaning. Also, these more proficient students (students 4 \& 5) were able to "unpack" the complex meaning systematically as indicated by the longer bars in Figure 2, as they were able to use more discourse in their descriptions. In contrast, students 1 to 3 struggled and did not display adequate command over these power words and/or could not explain relations and the constellations of meaning for the greater topic. From these findings it became clear that the students have to be made aware of the much needed disciplinary vocabulary they first need to master, in order to construct powerful scientific discourse and thereafter, how these power words relate to one another. In response to these findings, the succeeding cycle of the project was amended to include two additional stages: (1) the students had to read through a given section in their first-year textbook and then, within their groups, prepare a list of the terms (power words) needed to describe certain concepts. (2) This was followed up with group discussions and the construction of concept maps for each bigger concept, e.g. the eukaryotic 
nucleus. Concept maps has been shown to lighten cognitive load during learning (Kinchin 2017) and were meant to elucidate the constellations of meaning by revealing how these terms relate to one another. The group discussions were meant to encourage "science talk", which has been found to be cognitively less demanding than science writing and therefore good preparation for the writing part (Institute for Inquiry 2015).

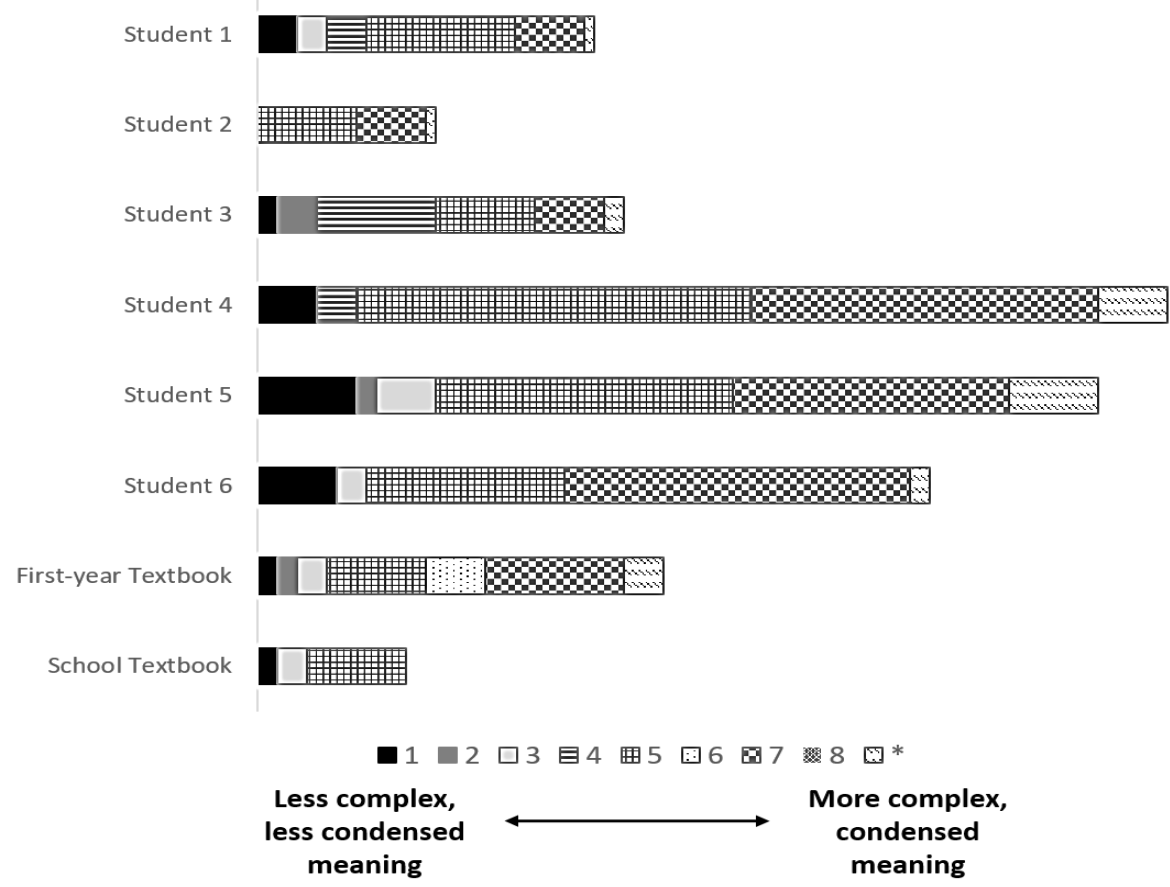

Figure 2. Semantic density analysis of students' discourse, as well as the school and first-year textbook. The bottom of the bars (towards the left) shows the proportion of simpler words used, progressing towards the most complex words at the top of the bars (towards the right).

When we considered and compared the discourse of the school and first-year biology textbooks (Figure 2), we found rather thought-provoking disparities. An academic stretch was obviously expected from the school to the first-year textbook, but the extent thereof was not anticipated. Our analyses exposed the magnitude of this gap and provided much needed insight into why students often grapple with the content and style of their first-year textbook. Not only is the volume substantially higher than that of the school textbook, but the increase in degree of complexity, as well as condensation of meaning, is significant. Moreover, this text-book's discourse is exceptionally condense with very little "unpacking" of meaning as shown by the compactness of this bar in Figure 2 (compared to students 4 to 6). Lecturers are mostly unaware of this extreme, steep increase in complexity. Students with proficient 
language skills and sound disciplinary background seem too able to navigate this transition, but a significant proportion of students find this gap very problematic. Educators should therefore be aware of this phenomenon and explore ways to assist first-year students during this transition when new skills need to be developed to allow epistemological access and learning for all students.

\section{Conclusions}

Academic discourse, including science discourse, uses 'power words and grammar' to package the knowledge of their fields into text (Martin 2013). Moreover, Biology and all other disciplines are characterized by their own unique genres and students need to develop skills to master the unique power compositions of each discipline to know how to scaffold and organize these genres for discourse and especially assessments. We believe that this study brought some aspects to light: Firstly, the are startling differences between the school and first-year biology textbooks in terms of volume, complexity and condensation of meaning. The gap between these two resources is substantial and educators need to be aware of this to assist students in this transition. Secondly, the variation in the proficiency and command of the students in terms of scientific vocabulary is noteworthy, as well as their ability to manipulate the forms of their additional language in a way that allow them to receive and pass on the thoughts they have developed in Biology. These students need time and opportunities to practice using the specialized language of scientific discourse. And finally, the scholarly approach of "collaborative pedagogy" (Jacobs 2007) revealed the importance of academic literacy, and how it contributes to the development of the fundamental skill of scientific discourse in the students. We believe that learning activities such as the one featured in this study, contributes to the development of students' scientific discourse, but also their identities as future scientists.

\section{References}

Ambitious Science Teaching. (2015). A discourse primer for science teachers. http://ambitiousscienceteaching.org/wp-content/uploads/2014/09/Discourse-Primer.pdf

Archila, P.A., Molin, J. \& Truscott de Mejía, A-M. (2018). Using formative assessment to promote argumentation in a university bilingual science course. International Journal of Science Education, doi: 10.1080/09500693.2018.1504176.

Boughey, C. (2002). Naming' Students' Problems: an analysis of language-related discourses at a South African university. Teaching in Higher Education, 7(3), 295-307. doi: 10.1080/13562510220144798.

Case, J., Marshall, D. \& Grayson, D. (2013). Mind the gap: Science and engineering education at the secondary-tertiary interface. South African Journal of Science, 109 (7/8), $1-5$. 
Dirrigl, F.J. \& Noe, M. (2018). The teacher writing toolkit: enhancing undergraduate teaching of scientific writing in the biological sciences. Journal of Biological Education, doi: 10.1080/00219266.2018.1501410.

Hurst, E. (2010). Language in Engineering and the built environment: examining students problems and impacts. Language, 1986.

Institute for Inquiry. Exploratorium. (2015). Science writing: a tool for learning science and developing language. www.exploratorium.edu.

Jacobs, C. (2007). Towards a critical understanding of the teaching of discipline-specific academic literacies: making the tacit explicit. Journal of Education, 41, 59-81. https://hdl.handle.net/10520/AJA0259479X_23.

Kinchin, I.M. (2017). Visualizing knowledge structures in biology: discipline, curriculum and student understanding. Journal of Biological Education 45 (4), 183-189. doi: 10.1080/00219266.2011.598178.

Kirby, N.F. (2010). Foundation science student performance explained. Insights gained at UKZN. $\quad$ https://www.assaf.org.za/files/2010/10/Kirby-Performance-explained.pdf (Accessed 28 November 2019).

Krajcik, J.S. \& Sutherland, L.M. (2010). Supporting students in developing literacy in science. Science, 328, 456-459.

Lee, J.S., Blackwell, S., Drake, J. \& Moran, K.A. (2014). Taking a leap of faith: Redefining teaching and learning in higher education through project-based learning. Interdisciplinary Journal of Problem-Based Learning, 8(2). doi:10.7771/15415015.1426.

Marshall, D. \& Case, J. M. (2010). d/Discourse in the learning of physics: the design of an introductory physics curriculum. African Journal of Research in MST Education, 14(2), 15-27. doi:10.1080/10288457.2010.10740679.

Martin, J.R. (2013). Embedded literacy: Knowledge as meaning. Linguistics and Education, 24, 23-37. doi:10.1016/j.linged.2012.11.006.

Maton, K. (2013). Making semantic waves: A key to cumulative knowledge building. Linguistics and Education 24, 8-22. doi: 10.1016/j.linged.2012.11.005.

Maton, K. (2014a). Knowledge and knowers: Towards a realist sociology of education. London: Routledge.

Maton, K. (2014b). A tall order? Legitimation Code Theory for academic language and learning. Journal of Academic Language and Learning, 8 (3), A34-A48.

Maton, K. \& Doran, Y.J. (2016). Semantic density: A translation device for revealing complexity of knowledge practices in discourse, part1 - wording. Onomázein. Revista semestral de lingüística, filogía y traducción, número especial SFL, 2017, 46-76.

McNeill, K.L., Lizotte D.J. \& Krajcik, J. (2005). Identifying teacher practices that support students' explanation in science. Annual meeting of the American Educational Research Association, April 2005, Montreal Canada.

Valencia, S. (2014). When high school students struggle with textbook reading. https://www.edutopia.org/blog/students-struggle-with-textbook-reading-sheila-valencia (Accessed 19 July 2018). 